\title{
Strom, Schlüssel für die Zukunft?
}

\author{
42. Internationale Fachtagung der Österreichischen Gesellschaft für Energietechnik im OVE, \\ 21. und 22. Oktober 2004 in Graz, Wohlfühlhotel Novapark
}

\section{Herzlich willkommen in Graz!}

Die kommende Fachtagung beschäftigt sich mit einem vitalen System in unserer Gesellschaft. Wir könnten feststellen, das Thema könnte auch „Leben und Wohlfühlen durch Strom" lauten. Die Abhängigkeit unseres Wohlstands von elektrischer Energie ist für jedermann fühlbar. Allerdings wird uns dies eigentlich nur dann bewusst, wenn sie fehlt. Dann wird es schnell klar, wie abhängig unsere Gesellschaft von einer tauglichen Stromversorgung ist.

Aber auch ein weiteres Prädikat ist dem Strom zuzuordnen. Strom ist ein wahrer Energiesparmeister. Er ist die Energieform, mit der wir Energie sparen, den Energieeinsatz steuern und damit einen wertvollen Beitrag zum aktiven Umweltschutz leisten.

Dass der Strombedarf dabei ständig steigt, ist in diesem Zusammenhang wenig überraschend. Vielfach überraschend war es jedoch, dass plötzlich der Strom knapp wurde, erlebt bei "Blackouts" in etlichen hochindustrialisierten Ländern auf allen Kontinenten. Was das für die europäische Energiewirtschaft zur Sicherung einer hochqualitativen Stromversorgung bedeutet, können wir mittlerweile vielfach aus aufmerksamen Medien entnehmen. Ist es doch mittlerweile ins Bewusstsein gelangt, dass ausreichende Erzeugungskapazitäten und Netze sowie geeignete Steuerungsanlagen unabdingbare Voraussetzung sind, um derartige Vorkommnisse zu vermeiden. Moderne Lösungen, die eine sichere Stromversorgung für unsere Zukunft garantieren, sind gefragt. Dieses Bewusstsein weiter zu fördern und die Qualität weiterhin zu garantieren, ist das Motto unserer diesjährigen Fachtagung.

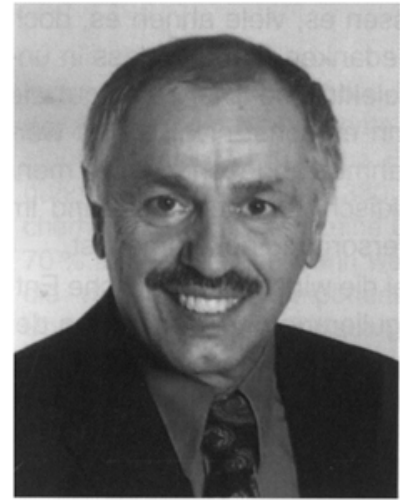

Dipl.-Ing. Walter Auer

Auch die Vergabe der OGE-Förderpreise 2004 für herausragende Dissertationen, Diplomarbeiten und HTL-Projektarbeiten findet wieder im Rahmen der Fachtagung statt.

In diesem Sinne wünschen wir Ihnen als Teilnehmer eine interessante und aufschlussreiche Fachtagung sowie einen erfolgreichen und angenehmen Aufenthalt in Graz, den Lesern der e \& viel Freude mit diesem Heft

Zum Schiuss gilt es noch, den Kollegen des Redaktionsteams, den Sponsoren, der Redaktion der e \& i und den Referenten zu danken, die durch ihre Arbeit den Erfolg der Tagung sicherstellen.

\section{Dipl.-Ing. Walter Auer OVE}

Vorstandsvorsitzender der ÖGE 